\title{
"Focusing" in Motivational Interviewing: development of a training tool for practitioners
}

\author{
Nina Gobat $\mathrm{PhD}^{\mathrm{a}}$, Lauren Copeland $\mathrm{PhD}^{\mathrm{b}}$, Rebecca Cannings-John $\mathrm{PhD}^{\mathrm{c}}$, Michael Robling \\ $\mathrm{PhD}^{\mathrm{d}}$, Judith Carpenter RD ${ }^{\mathrm{e}}$, Laura Cowley $\mathrm{MSc}^{f}$, Denitza Williams $\mathrm{PhD}^{\mathrm{g}}$, Julia Sanders PhD ${ }^{\mathrm{h}}$, \\ Shantini Paranjothy PhD' and Theresa Moyers PhD $^{\mathrm{j}}$
}

\author{
a Research Fellow, School of Medicine, Cardiff University, Cardiff, Wales, UK \\ b Research Associate, School of Medicine, Cardiff University, Cardiff, Wales, UK \\ c Research Fellow - Statistics, Centre for Trials Research, Cardiff University, Cardiff, Wales, UK \\ d Professor and Director of Population Health Trials, Centre for Trials Research, Cardiff University, Cardiff, Wales, UK \\ e Dietician and Motivational Interviewing Trainer, Derby Hospitals NHS Foundation Trust, Derby, UK \\ $f$ Doctoral Student, School of Medicine, Cardiff University, Cardiff, Wales, UK \\ g Research Associate, School of Medicine, Cardiff University, Cardiff, Wales, UK \\ $\mathrm{h}$ Reader in Midwifery, School of Healthcare Sciences, Cardiff University, Wales, UK \\ i Professor of Preventative Medicine and Director of Division of Population Medicine, School of Medicine, Cardiff \\ University, Cardiff, Wales, UK \\ j Professor of Psychology, University of New Mexico, Albuquerque, USA
}

\begin{abstract}
Rationale, aims and objectives: Motivational Interviewing (MI) is an individual-level approach to behaviour change that has been evaluated in over 600 randomised clinical trials across multiple settings. Increasingly, research efforts focus on how MI works and how it can best be integrated into public health and clinical programmes. As the application of MI expands, a key integration challenge involves specifying the focus of a conversation such that a practitioner might ignite and intensify a patient's internal motivation for change related to that focus. At present, this challenge is poorly conceptualised. We aimed to clarify the construct of "focusing" and to develop a practical tool that can be used to develop and assess practitioner competence.

Method: First we reviewed validated MI measures to elucidate current conceptualisations of focusing. Second, we identified practitioner speech acts that led to topic transitions. We then drafted the first version of MIFI. A gold standard rater, together with one expert MI and 3 non-expert MI raters, each used MIFI to coded 20 audio recordings from a feasibility study of MI and breastfeeding maintenance ( $n=170$ observations). Internal consistency and inter-rater reliability analyses were conducted.

Results: Published MI measures include 'focusing' as a strategy to agree a target change or to hold attention on that change target. We observed practitioners create or shift focus using 4 skills: questions, listening statements, giving information or meta-statements. Moderate to strong correlations were demonstrated between 4 of 5 global measures on the MIFI. Reliability estimates were good to excellent overall (5 coder ICCs $>0.65$ ), fair to excellent for the non-expert coding group (ICCs>0.55) and for the best coding pair (MI expert and non-expert ICCs $>0.52$ ).

Conclusion: We offer conceptual clarity about focusing in MI and have developed a tool to train practitioners in "focusing" when integrating MI into healthcare and public health interventions.
\end{abstract}

\section{Keywords}

Behavioural change, clinical practice, communication skills, complex intervention, fidelity assessment, focusing, measure, Motivational Interviewing (MI), person-centered healthcare, public health, staff training

\section{Correspondence address}

Dr. Nina Gobat, Division of Population Medicine, Cardiff University, 5th Floor Neuadd Meirionnydd, Heath Park, Cardiff, CF14 4YS, UK. E-mail: GobatNH@cardiff.ac.uk

Accepted for publication: 8 August 2017

\section{Introduction}

Motivational Interviewing (MI) is a collaborative, personcentered style of communication to elicit and strengthen a person's motivation to change [1]. Since it was developed in the late 1980s, over 600 published RCTs of the method have been conducted and meta-analyses show a small to medium effect across a range of settings, including 
smoking cessation [2], substance misuse [3,4], medical care [5,6], chronic disease [7], sexual health [8] and social work [9]. As MI expands to these different contexts, new challenges arise regarding how it can best be integrated into existing services so that practitioners working at the front line of healthcare and public health services can realise its effects with their patients.

The most recent iteration of MI describes four sequential processes through which MI is delivered (engaging, focusing, evoking, planning) [1] and this model offers a route to integrating MI into public health and healthcare interventions. Effective integration of MI into existing health services requires practitioners to effectively and efficiently arrive at the evoking process. Evoking represents the heart of MI, where practitioners elicit and differentially reinforce patient motivation toward change by identifying linguistic markers predictive of change [1014] (“change talk") to strengthen [11,15-17] these markers. To do that, practitioners need to first engage with their patients and then establish a mutually agreed focus on a health-related topic they wish to influence. In public and clinical health services these topics may be formulated within the clinical interaction as behaviours related to health promotion (e.g., breastfeeding, safe sexual practices) or health improvement (e.g., smoking cessation, weight loss). However, public policy and programme goals often focus on outcomes that may only partially map to the conversations about change embedded in them. Thus, while conversations about change are often a core component of programmes in these settings, these change foci may be weakly formulated and compete for priority with other tasks. For example, a maternal and child health service may aim "to improve maternal and child health outcomes" and may require practitioners to address a range of topics with parents, such as antenatal smoking and breastfeeding intention, as well as to complete other tasks such as physical health assessment or safety monitoring. The challenge to MI integration is that practitioners need to formulate and then raise their agenda related to health behaviour change in a way that maintains patient engagement and invites their collaboration. Once a focus on a topic has been jointly established, practitioners then need to ensure the conversation progresses in the direction of that topic. This may involve re-directing the conversation to hold focus on the agreed topic if it shifts into other areas. Skilful focusing then provides an anchor for the evoking process such that change talk (i.e., patient statements that favour change) might be recognised and reinforced in that area. Likewise, sustain talk (i.e., patient statements that favour the status quo) can be recognised and diminished. For example, if the health behaviour focus is breastfeeding then the patient statement "I'd like to breastfeed my baby" would be recognised as change talk and the patient statement "but no-one I know has ever done it" would be recognised as sustain talk. In the evoking process, practitioners would primarily seek to elicit and expand patient talk about change.

For practitioners working with a person-centered ethos in public health and healthcare contexts, there are three key challenges with focusing. The first involves identifying and formulating the different topics that might be discussed. The second is to prioritise a single focus from multiple topics. A strategy such as agenda mapping may be helpful for practitioners in addressing these two challenges. The third challenge for practitioners is to hold focus on the agreed topic in such a way that progress can be made regarding commitment to change. Efforts to work in a person-centered way can leave practitioners feeling inhibited from raising certain subjects or from re-directing the conversation when it moves off topic for fear of damaging rapport. Practitioners may simply be unsure how to get going with these conversations, may lack confidence in how to respond if patients express reluctance to address a topic, or may easily become diverted when addressing the change target. This challenge has been less well described in writings on MI thus far.

We identified these practice challenges through our work in two maternal and child public health programmes. The first, Building Blocks, was a pragmatic, open, individually randomised controlled trial that aimed to evaluate the effectiveness of the Family Nurse Partnership (FNP) programme added to the care usually provided through primary care, public health and social services to first-time mothers under 19 years of age in England [18]. FNP is a structured home-visiting programme, delivered individually by family nurses (FNs), that aims to address the poor outcomes commonly experienced by infants born into socioeconomic deprivation and to teenage mothers $[19,20]$. Family Nurses were taught MI as a method of delivering programme materials in an effort to enhance patient engagement and reduce attrition [21]. The second programme was Mam-kind, a non-randomised multi-site study to test the feasibility of delivering MI-based breastfeeding support to mothers living in areas with high levels of social deprivation in the UK [22]. Peer supporters were trained to use MI as the method of programme delivery. In both programmes, practitioners were required to use MI to raise and conduct health-promoting conversations, for example, regarding expectant mother's breastfeeding intentions. In process evaluations of these studies we identified the need for a training tool that might help practitioners obtain conceptual clarity and skilfulness in focusing during a MI conversation, particularly related to raising and holding focus on one topic. Following well recognised methodology [23], we aimed therefore to develop a tool that would help practitioners develop skilfulness in establishing and holding focus on a health behaviour topic in an MI-informed intervention.

\section{Methods}

\section{Review of existing measures}

We reviewed the literature to identify if and how focusing had been assessed in published measures of MI. The reasons for this were twofold. First, we wanted to identify any published work with similar intent to ensure we might build on, rather than duplicate, efforts by other researchers 
Table 1 Data sources used in the development of MIFI

\begin{tabular}{|c|c|c|c|}
\hline & Data source & Description of data & Description of sample \\
\hline \multirow[t]{2}{*}{$\begin{array}{l}\text { Construct } \\
\text { development }\end{array}$} & $\begin{array}{l}\text { Building Blocks } \\
\text { Pragmatic, open, individually randomised } \\
\text { controlled trial evaluating effectiveness of } \\
\text { the Family Nurse Partnership (FNP), a } \\
\text { structured home-visiting programme, added } \\
\text { to care usually provided through primary } \\
\text { care, public health and social services to } \\
\text { first-time mothers under } 19 \text { years of age in } \\
\text { England [29]. }\end{array}$ & $\begin{array}{l}\text { Real consultation between } \\
\text { family nurses and young } \\
\text { mothers in the antenatal } \\
\text { and early infancy period. }\end{array}$ & $\begin{array}{l}\text { Purposive sample of } 7 \text { audio- } \\
\text { recordings. }\end{array}$ \\
\hline & $\begin{array}{l}\text { Mam-kind } \\
\text { Non-randomised multi-site feasibility study } \\
\text { to assess MI-based breast-feeding support to } \\
\text { mothers living in areas with high levels of } \\
\text { social deprivation in England and Wales } \\
\text { [64]. }\end{array}$ & $\begin{array}{l}\text { Real consultations between } \\
\text { peer supporters and } \\
\text { breastfeeding mothers in } \\
\text { the early neonatal period }\end{array}$ & $\begin{array}{l}\text { Purposive sample of } 21 \text { audio- } \\
\text { recordings. }\end{array}$ \\
\hline \multirow[t]{2}{*}{$\begin{array}{l}\text { Piloting and } \\
\text { training of raters }\end{array}$} & Training DVDs & $\begin{array}{l}\text { Simulated patient } \\
\text { encounters. } \\
\text { Expert demonstrations of } \\
\text { strong and weak practice } \\
\text { used for training }\end{array}$ & $\begin{array}{l}\text { Purposive sample of } 5 \text { training } \\
\text { videos reflecting high and low MI } \\
\text { skilfulness. }\end{array}$ \\
\hline & $\begin{array}{l}\text { Mam-kind } \\
\text { (As above) }\end{array}$ & As above & $\begin{array}{l}\text { Purposively selected sample of } 9 \\
\text { audio-recordings to reflect mix in } \\
\text { skill level. }\end{array}$ \\
\hline Reliability & $\begin{array}{l}\text { Mam-kind } \\
\text { (As above) }\end{array}$ & As above & $\begin{array}{l}\text { Random sample of } 20 \text { audio- } \\
\text { recordings }\end{array}$ \\
\hline
\end{tabular}

working in this field. Second, since the way in which a construct is conceptualised will inform how it is measured, we aimed to understand how 'focusing' had been conceptualised in empirical work to date. We identified 2 systematic reviews of MI measures [24,25] and updated the most recent of these by running the following search strategy on MEDLINE, EMBASE, PsycINFO and Web of Science from Jan 2013 to Dec 2016 ((motivation OR motivational) AND (interview OR interviewing) OR (motivational interviewing)) AND (intervention fidelity OR skill OR evaluation) AND (validity OR reliability)) [25]. Additional measures were identified through the Motivational Interviewing Network of Trainers [26]. We included published measures of MI or MI related interventions that included objective assessment of practitioner efforts to establish and/or maintain direction on a change target (including structuring statements). We excluded unpublished measures, self-report measures and those that assessed direction but as an MI-inconsistent behaviour.

\section{Data and sampling}

Table 1 provides an overview and summary of data used at different time points in the development of the
Motivational Interviewing Focusing Instrument (MIFI). We used 3 sources of data in developing MIFI: simulated, expert practice samples and real consultation data from 2 MI-based clinical studies. Real consultation recordings were available from Building Blocks $(n=139)$ and Mamkind ( $n=78)$. These datasets had been coded to assess MI fidelity using version 3.1.1 and version 4.2 respectively of the Motivational Interviewing Treatment Integrity Scale (MITI) [27,28]. We purposively sampled audio recordings reflecting variable practice in MI for the inductive phase of this work. From the Building Blocks dataset, we selected 7 audio recordings with variability in scores on the “direction” subscale of MITI3.1.1. We used 21 audio recordings that had been coded during process evaluation for the Mam-kind study. These audio-recordings had been selected to represent key intervention time points. We then randomly sampled 20 audios from the remaining Mamkind dataset $(n=56)$ only for reliability testing. Existing ethical approvals covered the use of these data.

\section{Development of MIFI}

We developed a first version of the MIFI-based on findings from our review of measures and inductive exploratory work. We used the four-process model of MI (engaging, 
focusing, evoking, planning) [1] and earlier conceptual development work conducted by our group [29] as a conceptual foundation to inform inductive exploration of how focusing is enacted in consultations between family nurses and young mothers [18] and between peer supporters and breastfeeding mothers in the neonatal period (7 Building Blocks audios, 21 Mam-kind audios, Table 1). Working with these data, we isolated conversation exchanges and practitioner utterances that resulted in transitions toward or away from the topic of interest. We described and classified practitioner utterances as a communication skill. Our focus on practitioner utterances as opposed to patient utterances or both reflects the intended use of our measure as a teaching or supervision tool. We used NVivo 10 software to support these analyses. We (NG and LCop) then refined MIFI through an iterative pilot process of using the measure with audio-recordings purposively sampled to reflect a range of skilfulness in focusing using MI (5 Training audios, 9 Mam-kind audios, Table 1).

\section{Recruitment and training of raters}

Three data coders with little or no experience of MI (LCow, DW, CB) and one experienced MI rater (JC) were recruited and trained in the use of MIFI over a 3-week period in October 2016. Training involved an initial 3.5 hour face-to-face training with 21.5 hour face-to-face follow-up meetings. Between each meeting, raters independently coded a sample of audio-recordings. Raw scores were compared and discussed at follow-up meeting and the group jointly coded an audio to identify difficulties and discrepancies. We selected a random sample of 20 audio recordings from 57 recordings that were available from the Mam-kind study. A randomly selected 20 minute segment from each of these audio-recordings was coded by all raters as well as by a gold standard coder (LCop). Each rater completed this task independently and within 3 weeks of the training being completed.

\section{Coding}

Each recording generated 5 Global ratings (Establishing Focus, Holding Focus, Developing depth and momentum, Partnership, Empathy), proportion scores for breastfeeding and behaviour counts for establishing focus on breastfeeding. Each Global rating was coded from 1 (weaker practice) to 5 (stronger practice). An additional category of zero (not applicable) was given where focus has already been established prior to the randomly allocated 20 minute segment. Proportion scores were summarised from 1 (little evidence of the target change being discussed) to 5 (substantial evidence of the target change being discussed).

\section{Statistical analysis}

Descriptive statistics (mean, standard deviations, minimum and maximum) were produced for each score and by rater.
Internal consistency of the summary scale that is formed by the global scores was explored by using factor analysis. The Kaiser-Meyer-Olkin (KMO) values and Bartlett's test Sphericity were run to determine whether factor analysis could be performed. The relationship between global scores was examined using Pearson correlation coefficient and exploratory factor analysis with no rotation to examine the construct validity of global scales. A loading factor of $>0.4$ was the cut-off point for item retention [30]. Interrater reliability (IRR) statistics for all raters were estimated using the intra-class coefficient (ICC) alongside 95\% confidence intervals for the EF counts [31]. This approach yields a more conservative measure of inter-rater reliability than Cronbach's alpha and is the recommended approach considering our data are ordinal, more than 2 coders were used and all coders evaluated all available samples [32]. This is a fully crossed design in which all 5 raters each rated the same 20 recordings and ICCs were obtained using a 2-way random effects model with absolute agreement (ICC(2)). This analytic approach is consistent with other measures of MI $[27,28]$ and we report average measure ICCs for ease of comparability. Commonly-cited thresholds for qualitative ratings of agreement based on ICC values consider IRR being poor for ICC values less than $0.4,0.4$ to 0.59 is fair, 0.6 to 0.74 is good and 0.75 to 1 is excellent [33]. IBM SPSS Statistics version 20.0 [34] was used for all statistical analyses.

\section{Results}

\section{Review of measures of MI}

We screened 112 citations and identified 31 measures for review. Of these, 12 measures met our inclusion criteria (Table 2). Excluded measures did not assess focusing, included being directive as an MI inconsistent behaviour (consistent with earlier iterations of MI), primarily assessed evoking or were rated using self-report.

The way in which focusing has been included in published measures of MI reveal how it has been conceptualised. Six measures included items that assess skilfulness in establishing focus, that is, as an upfront process of agreeing a change target. Establishing focus was assessed as agenda mapping [35-37] or raising the subject $[38,39]$. A more recently developed measure included focusing as a process of guiding patients toward a change target [40]. MITI3.1 included an assessment of the extent to which a practitioner is able to hold focus on the target behaviour [41]. This item was replicated in the PatientCentred Communication Coding System [42]. Items in AMIGOS, a measure of group MI, related to developing depth and momentum in a conversation about change, thereby extending the concept of holding focus [43]. Topic shifts were captured in 2 measures that tallied structuring or meta-statements indicating a transition from one part of a session to another [44-46]. While the majority of included measures assessed focusing at the level of process $(\mathrm{n}=11)$, one included defining content [47]. This was a 
Table 2 Foc using included in existing measures of MI

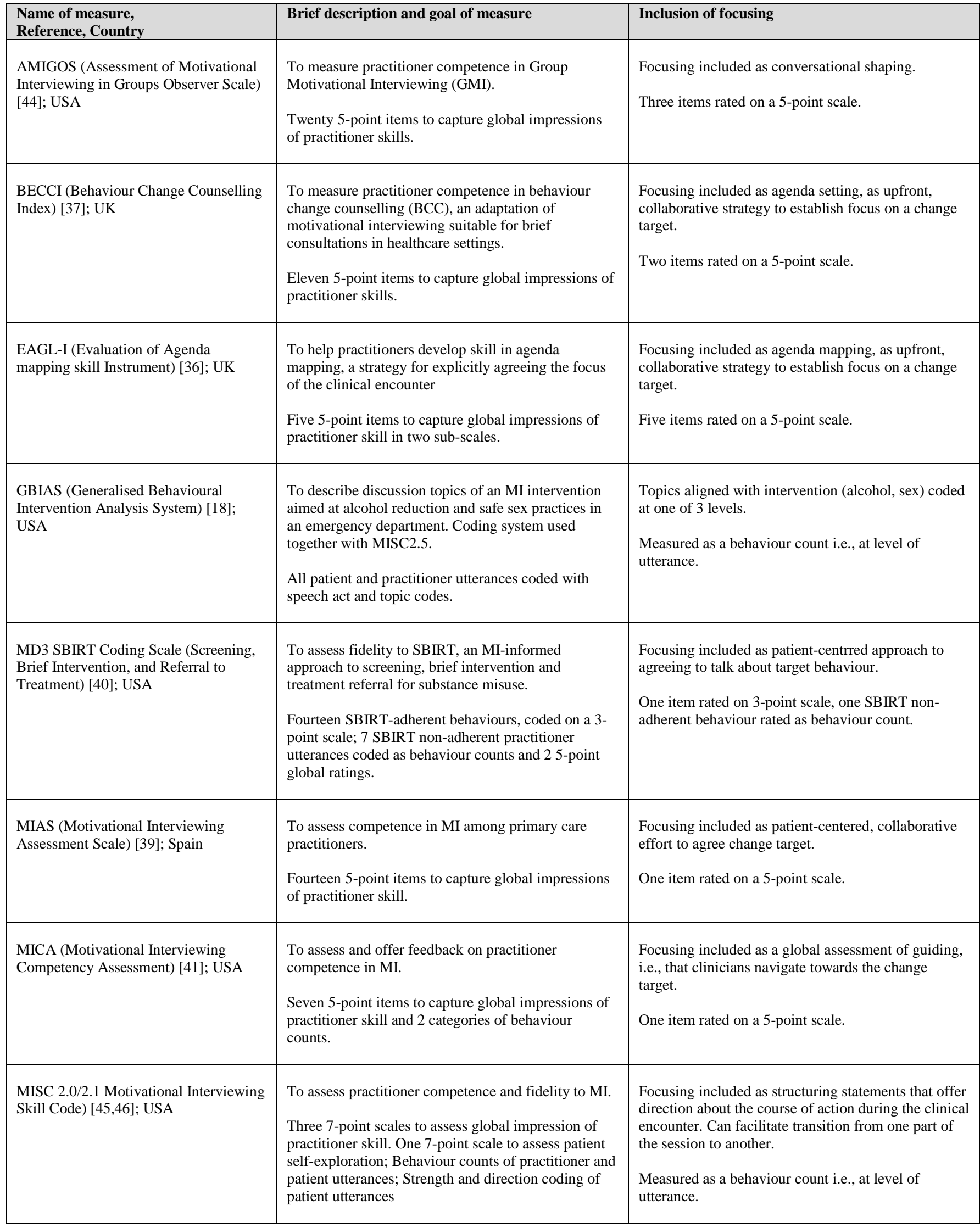




\begin{tabular}{|c|c|c|}
\hline $\begin{array}{l}\text { MITI 3.1.1 (Motivational Interviewing } \\
\text { Treatment Integrity) [42]; USA }\end{array}$ & $\begin{array}{l}\text { To assess practitioner competence and fidelity to MI. } \\
\text { Five 5-point items to capture global impressions of } \\
\text { practitioner skill. Behaviour counts of practitioner } \\
\text { utterances assigned to one of } 7 \text { categories. }\end{array}$ & $\begin{array}{l}\text { Focusing included as a global assessment of } \\
\text { direction, i.e., that clinicians maintain focus on target } \\
\text { behaviour. } \\
\text { One item rated on a 5-point scale. }\end{array}$ \\
\hline $\begin{array}{l}\text { One Pass } \\
\text { McMaster et al } 2015 \text { [38]; UK/USA }\end{array}$ & $\begin{array}{l}\text { To assess practitioner competence and fidelity to MI. } \\
\text { Twenty-three items rated on a 7-point scale. }\end{array}$ & $\begin{array}{l}\text { Focusing included as agenda setting, as upfront, } \\
\text { collaborative strategy to establish focus on a change } \\
\text { target. } \\
\text { One item rated on a seven-point scale. }\end{array}$ \\
\hline $\begin{array}{l}\text { PCCCS (Patient-Centered } \\
\text { Communication Coding System) [43]; } \\
\text { USA }\end{array}$ & $\begin{array}{l}\text { To assess patient-centered communication techniques } \\
\text { for a paediatric obesity intervention. Measure adapted } \\
\text { from MITI3. } \\
\text { Four 5-point items to capture global impressions of } \\
\text { practitioner skill. Behaviour counts of practitioner } \\
\text { utterances assigned to one of } 12 \text { categories. }\end{array}$ & $\begin{array}{l}\text { Focusing included as a global assessment of } \\
\text { direction, i.e., that clinicians maintain focus on target } \\
\text { behaviour (as in MITI3). } \\
\text { One item rated on a 5-point scale. }\end{array}$ \\
\hline $\begin{array}{l}\text { SCOPE (Motivational Interviewing } \\
\text { Sequential Code for Observing Process } \\
\text { Exchanges) [47]; USA }\end{array}$ & $\begin{array}{l}\text { To assess MI communication exchanges, with a focus } \\
\text { on sequential information, in order to examine } \\
\text { theoretical constructs in relation to outcome. } \\
\text { Sequential coding of therapist utterances and patient } \\
\text { utterances assigned to one of } 28 \text { categories. }\end{array}$ & $\begin{array}{l}\text { Focusing included as structuring statements that offer } \\
\text { direction about the course of action during the clinical } \\
\text { encounter. Can facilitate transition from one part of } \\
\text { the session to another. } \\
\text { Measured as a behaviour count i.e., at level of } \\
\text { utterance. }\end{array}$ \\
\hline
\end{tabular}

Table 3 Description of items in MIFI

\begin{tabular}{|c|c|c|}
\hline \multicolumn{2}{|c|}{ Items } & Description \\
\hline \multirow{5}{*}{$\begin{array}{l}\text { Global measure } \\
\text { Scale rating from } \\
1 \text { (low) to } 5 \\
\text { (high). }\end{array}$} & Establishing focus & Establishes focus on a topic of conversation in a strategic and purposeful way \\
\hline & Holding focus & Holds attention on the topic \\
\hline & $\begin{array}{l}\text { Developing depth and } \\
\text { momentum }^{1}\end{array}$ & Makes progress in understanding the patient's perspective about that topic \\
\hline & Partnership $^{2}$ & Conveys an understanding that expertise and wisdom reside within the patient. \\
\hline & Empathy $^{2}$ & Understands or makes an effort to grasp the patient's perspective and experience \\
\hline \multirow{3}{*}{$\begin{array}{l}\text { Behaviour counts } \\
\text { Count assigned to } \\
\text { practitioner } \\
\text { statement }\end{array}$} & Establish focus & $\begin{array}{l}\text { Uses a meta-statement, responds to a cue e.g., uses listening statement, asks a } \\
\text { question gives information to establish focus on a topic. }\end{array}$ \\
\hline & Hold focus & $\begin{array}{l}\text { Gives any response that influences the conversation to stay focused on the } \\
\text { agreed topic of change }\end{array}$ \\
\hline & Other topic & $\begin{array}{l}\text { Gives any response that influences the conversation so that it moves to another } \\
\text { topic }\end{array}$ \\
\hline \multirow{2}{*}{ Topic summaries } & Proportion score & How much time was spent discussing each topic (rated on scale of 1-5) \\
\hline & $\begin{array}{l}\text { Number of successful } \\
\text { EF }\end{array}$ & $\begin{array}{l}\text { Three EF behaviour counts in a row results in practitioner having successfully } \\
\text { established focus on a topic. }\end{array}$ \\
\hline
\end{tabular}

\footnotetext{
${ }^{1}$ Conceptualisation influenced by AMIGOS
}

${ }^{2}$ Global measure from MITI4.2 


\section{Table 4a Use of MIFI to draw attention to shifts in foc us of a conversation between an expectant mother and a breastfeeding peer supporter - weaker practice}

[Note how the peer supporter inadvertently shifts focus from talk about breastfeeding to talk about labour in the following exchange].

\begin{tabular}{|c|c|c|c|}
\hline & Interaction between mum and peer supporter & Use of skill in focusing & MIFI code \\
\hline 1 & P/S: So have you thought much about breastfeeding? & $\begin{array}{l}\text { Practitioner uses a question to establish } \\
\text { focus on the topic of breastfeeding }\end{array}$ & $\begin{array}{l}\text { Establishing focus using } \\
\text { a question (EF-Q) }\end{array}$ \\
\hline 2 & $\begin{array}{l}\text { Mum: Yeah its something I thought of really early on to be } \\
\text { honest. I went through a stage of umm-ing and ah-ing ... } \\
\text { obviously I know it's the best thing for the baby, but, I don't } \\
\text { know how it will fit in with my you know my lifestyle ... }\end{array}$ & Mum reflects some ambivalence here & \\
\hline 3 & $\begin{array}{l}\text { P/S: So you want to think about how it is going to work for } \\
\text { you. }\end{array}$ & $\begin{array}{l}\text { Practitioner response using a listening } \\
\text { statement that picks up on a patient cue }\end{array}$ & $\begin{array}{l}\text { Establishing focus } \\
\text { responding to a cue (EF- } \\
\text { Cue) }\end{array}$ \\
\hline 4 & $\begin{array}{l}\text { Mum: Yeah, I like to plan ahead, and to know what expect } \\
\text { so perhaps for that first week I am just going to be lying } \\
\text { around and breastfeeding and if I don't get the dishes done } \\
\text { is not the end of the world; do you know what I mean? }\end{array}$ & $\begin{array}{l}\text { Mum continues to talk about } \\
\text { breastfeeding }\end{array}$ & \\
\hline 5 & PS: So to expect that you have to go with the flow with it & $\begin{array}{l}\text { Practitioner responds using a listening } \\
\text { statement that picks up on a patient cue }\end{array}$ & $\begin{array}{l}\text { Establishing focus } \\
\text { responding to a cue (EF- } \\
\text { Cue) }\end{array}$ \\
\hline 6 & $\begin{array}{l}\text { Mum: I kind of have that mindset with labour as well, you } \\
\text { know and I have my birth plan, but you don't know what is } \\
\text { going to happen on the day }\end{array}$ & $\begin{array}{l}\text { The idea of "going with the flow" leads } \\
\text { to the topic of conversation shifting to } \\
\text { talk about labour. }\end{array}$ & \\
\hline 7 & $\begin{array}{l}\text { P/S: Yeah, it might go one way or it might go the other, like } \\
\text { birth }\end{array}$ & $\begin{array}{l}\text { Practitioner continues to follow the } \\
\text { topic of conversation raised by the mum } \\
\text { and misses an opportunity to link it back } \\
\text { to breastfeeding }\end{array}$ & $\begin{array}{l}\text { Other topic (shift to } \\
\text { labour) }\end{array}$ \\
\hline 8 & $\begin{array}{l}\text { Mum: Yes as long as it all comes out and its healthy and } \\
\text { happy }\end{array}$ & & \\
\hline 9 & P/S: So, what are you hoping? & $\begin{array}{l}\text { Practitioner continues to follow } \\
\text { conversation about labour and the } \\
\text { initial window of opportunity to talk } \\
\text { more about breastfeeding has closed. }\end{array}$ & $\begin{array}{l}\text { Other topic (shift to } \\
\text { labour) }\end{array}$ \\
\hline 10 & $\begin{array}{l}\text { Mum: Well I was hoping to try the birthing pool if it's just } \\
\text { for pain relief }\end{array}$ & Mum continues discussion about labour & \\
\hline
\end{tabular}

\section{Table 4b Use of MIFI to draw attention to shifts in foc us of a conversation between an expectant mother and a breastfeeding peer supporter - better practice}

[Note how a subtle shift in skill at line 7 allows the peer supporter to maintain focus on the topic of breastfeeding].

\begin{tabular}{|c|c|c|c|}
\hline & Interaction between mum and peer supporter & Use of skill in focusing & MIFI code \\
\hline 1 & P/S: So have you thought much about breastfeeding? & $\begin{array}{l}\text { Practitioner uses a question to } \\
\text { establish focus on the topic of } \\
\text { breastfeeding }\end{array}$ & $\begin{array}{l}\text { Establishing focus using a } \\
\text { question }(E F-Q)^{*}\end{array}$ \\
\hline 2 & $\begin{array}{l}\text { Mum: Yeah its something I thought of really early on to } \\
\text { be honest. I went through a stage of umm-ing and ah-ing } \\
\ldots \text { Obviously I know it's the best thing for the baby, but, } \\
\text { I don't know how it will fit in with my you know my } \\
\text { lifestyle ... }\end{array}$ & Mum reflects some ambivalence here & \\
\hline 3 & $\begin{array}{l}\text { P/S: So you want to think about how it is going to work } \\
\text { for you. }\end{array}$ & $\begin{array}{l}\text { Practitioner response using a } \\
\text { listening statement that picks up on a } \\
\text { patient cue }\end{array}$ & $\begin{array}{l}\text { Establishing focus } \\
\text { responding to a cue (EF- } \\
\text { Cue) }\end{array}$ \\
\hline 4 & $\begin{array}{l}\text { Mum: Yeah, I like to plan ahead, and to know what } \\
\text { expect so perhaps for that first week I am just going to be } \\
\text { lying around and breastfeeding and if I don't get the } \\
\text { dishes done is not the end of the world; do you know what } \\
\text { I mean? }\end{array}$ & $\begin{array}{l}\text { Mum continues to talk about } \\
\text { breastfeeding }\end{array}$ & \\
\hline 5 & PS: So to expect that you have to go with the flow & $\begin{array}{l}\text { Practitioner responds using a } \\
\text { listening statement that picks up on a } \\
\text { patient cue }\end{array}$ & $\begin{array}{l}\text { Establishing focus } \\
\text { responding to a cue (EF- } \\
\text { Cue) }\end{array}$ \\
\hline 6 & $\begin{array}{l}\text { Mum: I kind of have that mindset with labour as well, you } \\
\text { know and I have my birth plan, but you don't know what } \\
\text { is going to happen on the day }\end{array}$ & $\begin{array}{l}\text { The idea of "going with the flow" } \\
\text { leads to the topic of conversation } \\
\text { shifting to talk about labour. }\end{array}$ & \\
\hline 7 & P/S: Yeah, it might go one way or it might go the other, so & Practitioner continues to follow the & Hold focus plus $(\mathrm{HF}+)-a$ \\
\hline
\end{tabular}




\begin{tabular}{|c|l|l|l|}
\hline & $\begin{array}{l}\text { what are you hoping might happen with regard to } \\
\text { breastfeeding? }\end{array}$ & $\begin{array}{l}\text { topic of conversation raised by the } \\
\text { mum and then steers the conversation } \\
\text { back to talk about breastfeeding by } \\
\text { asking a question about breastfeeding. } \\
\text { The question is also designed to } \\
\text { stimulate self-reflection by mum. }\end{array}$ & $\begin{array}{l}\text { hold focus code indicates the } \\
\text { practitioner sustains } \\
\text { attention on the topic; the } \\
\text { plus indicates use of a } \\
\text { question designed to develop } \\
\text { depth in discussion. }\end{array}$ \\
\hline 8 & $\begin{array}{l}\text { Mum: well I'd like to be able to breastfeed if I can, and I } \\
\text { guess I'm hoping that it is easier than I imagine! }\end{array}$ & $\begin{array}{l}\text { Mum moves back toward talking } \\
\text { about breastfeeding }\end{array}$ & \\
\hline 9 & $\begin{array}{l}\text { P/S: And it may well be. What would help you feel most } \\
\text { prepared to give it a good go? }\end{array}$ & $\begin{array}{l}\text { Practitioner continues the focus on } \\
\text { breastfeeding and }\end{array}$ & Hold focus (HF+) \\
\hline 10 & $\begin{array}{l}\text { Mum: Well, for starters, I'd like to know where to get } \\
\text { help if things get tough and to know a bit more about what } \\
\text { to expect. }\end{array}$ & & \\
\hline
\end{tabular}

*Coding convention requires that practitioners receive 3 Establishing Focus (EF) behaviour counts in a row before being allocated a Holding Focus (HF) code

\section{Table 5 Overall mean (standard deviations), min and max score by Global measure ${ }^{1}$ and rater $(n=20$ recordings)}

\begin{tabular}{|c|c|c|c|c|c|c|}
\hline Global measure & Expert 1 & Expert 2 & Non-expert 1 & Non-expert 2 & Non-expert 3 & Overall \\
\hline Establishing Focus ${ }^{2}$ & $\begin{array}{c}2.3(1.3) \\
0 \text { to } 5\end{array}$ & $\begin{array}{c}2.65(1.31) \\
0 \text { to } 4\end{array}$ & $\begin{array}{c}2.65(1.35) \\
0 \text { to } 4\end{array}$ & $\begin{array}{c}2.75(1.8) \\
0 \text { to } 5\end{array}$ & $\begin{array}{c}2(1.45) \\
0 \text { to } 4\end{array}$ & $2.47(1.45)$ \\
\hline Holding Focus & $\begin{array}{c}3.55(1.1) \\
1 \text { to } 5 \\
\end{array}$ & $\begin{array}{c}3.5(1.1) \\
1 \text { to } 5\end{array}$ & $\begin{array}{l}3.2(1.15) \\
1 \text { to } 5 \\
\end{array}$ & $\begin{array}{c}3.15(1.18) \\
1 \text { to } 5\end{array}$ & $\begin{array}{c}3(0.97) \\
1 \text { to } 5\end{array}$ & $3.28(1.1)$ \\
\hline $\begin{array}{l}\text { Developing depth and } \\
\text { momentum }\end{array}$ & $\begin{array}{c}2.5(0.83) \\
1 \text { to } 4 \\
\end{array}$ & $\begin{array}{c}2.1(0.79) \\
1 \text { to } 4 \\
\end{array}$ & $\begin{array}{c}2.6(0.94) \\
1 \text { to } 4 \\
\end{array}$ & $\begin{array}{c}2.65(0.75) \\
1 \text { to } 4 \\
\end{array}$ & $\begin{array}{c}2.85(0.81) \\
1 \text { to } 4\end{array}$ & $2.54(0.85)$ \\
\hline Partnership & $\begin{array}{c}2.55(0.83) \\
1 \text { to } 4\end{array}$ & $\begin{array}{c}2.05(0.6) \\
1 \text { to } 3\end{array}$ & $\begin{array}{c}3.1(0.85) \\
1 \text { to } 4\end{array}$ & $\begin{array}{c}2.5(0.89) \\
1 \text { to } 4\end{array}$ & $\begin{array}{c}2.8(0.83) \\
1 \text { to } 4\end{array}$ & $2.6(0.86)$ \\
\hline Empathy & $\begin{array}{c}2(0.73) \\
1 \text { to } 3\end{array}$ & $\begin{array}{c}1.9(0.91) \\
1 \text { to } 4\end{array}$ & $\begin{array}{c}2.40(1.1) \\
1 \text { to } 4\end{array}$ & $\begin{array}{c}2.1(0.64) \\
1 \text { to } 3\end{array}$ & $\begin{array}{c}3.05(0.89) \\
1 \text { to } 4\end{array}$ & $2.29(0.95)$ \\
\hline
\end{tabular}

${ }^{1}$ Scores rated 1-5, with 5 indicating high score

${ }^{2}$ Establishing focus $=0$ indicates that focus had been established prior to the start of the randomly identified

20 minute segment being rated.

process measure used in a study where 2 change targets were addressed.

\section{Development of MIFI}

The design of the MIFI (Table 3) mirrors that of the Motivational Interviewing Treatment Integrity (MITI4.1) measure $[28,48]$ in assessing practitioner skill using global measures and behaviour counts. Moreover, the 2 relational global measures from the MITI4.2 (Partnership and Empathy) are included in the MIFI with some minor adjustments. These global measures capture the foundational relational quality essential to MI practice. Global measures require assessors to allocate a score between 1 and 5 that best represents their overall impression of practitioner skill. MIFI also includes global measures of practitioner skill in Establishing Focus and Holding Focus as well as the extent to which they were able to Developing Depth and Momentum when exploring the topic.

MIFI behaviour counts require assessors to note practitioner speech acts and to link these to the topic being focused on. Topics need therefore to be clearly prespecified and MIFI includes a pro-forma for topic specification. The datasets we used to develop MIFI had pre-specified topics aligned with programme outcomes.

For example, breastfeeding was the primary topic for discussion in Mam-kind. In relation to these pre-specified topics, we observed that practitioner utterances either initiated a topic or drew attention to the topic when the patient raised it. Focus was established or held when practitioners framed their utterances in the context of the change target. Where the content of utterances was ambiguous or pointed to a new topic then the focus of the conversation shifted.

We identified 4 forms of practitioner utterances that led to a shift in focus (Table 4a \& 4b). First, practitioners used enquiry in the form of open and closed questions. For example, "how is breastfeeding going?". Closed questions aimed at gathering facts were common. Second, practitioners used a listening statement or reflection to draw attention to something the patient had said to create a focus. For example, in response to a patient who said " $I$ 'd like to (breastfeed) but If I can't I'll look at other options" the practitioner responded, "So breastfeeding is definitely an option for you". Third, practitioners gave information to establish focus, for example, "Initially we recommend breastfeeding every three hours". Finally, practitioners used statements to comment on the process of conversation, that is, a meta-statement or structuring statement. For example, “Well, let's talk about that (breastfeeding) now". Practitioners most commonly used meta-statements to draw attention to the fact that the conversation had moved off topic and to redirect it. For example, “We're going a bit off track now”. These metastatements were distinct from listening statements, as they were not an effort to mirror what the patient had said. At times, practitioners were observed to use multiple skills in one utterance. For example, a listening statement may be 
followed with a question to create focus. Some practitioner utterances also fell into multiple categories. For example, a meta-statement could also be classified as a question. For example, "Do you think we're going a bit off track now?" The extent to which a shift toward or away from the topic of interest was produced was dependent on the degree of lexical cohesion between the content of these utterances and that topic.

These observations lead to the sub-classification of MIFI behaviour counts and to rules that would allow for reliable coding. Two example dialogues are presented in Table 4a \& 4b to illustrate the subtle shifts in conversational focus and how MIFI captures these.

\section{Reliability testing}

Five raters (2 experts / 3 non-experts) coded 20 audio recordings each. Table 5 shows summary statistics for each of the global scales by rater.

\section{Internal-consistency of the global scales}

A KMO value of 0.697 and Bartlett Spherical test was significant at $<0.001$ in an exploratory factor analysis, indicating that a factor analysis was feasible. Moderate to strong correlations were demonstrated between all global scores (Holding Focus, Developing Depth and Momentum, Partnership and Empathy) apart from Establishing Focus and all other global scales $(\mathrm{r}<0.22)$. The factor analysis showed that all the 5 global scales were found to load on a single factor for the full sample and explained $55.18 \%$ of the variance. Factor loadings for each global scale ranged from 0.079 (Establishing Focus) to 0.858 (Developing Depth and Momentum) (Table 6), indicating that Establishing Focus global score does not correlate well with the other scores.

\section{Table 6 Global ratings: factor loadings}

\begin{tabular}{|l|c|}
\hline Global ratings & Factor loadings \\
\hline Establishing Focus & 0.079 \\
\hline Holding Focus & 0.409 \\
\hline Developing depth and momentum & 0.858 \\
\hline Partnership & 0.728 \\
\hline Empathy & 0.685 \\
\hline
\end{tabular}

\section{Inter-rater reliability}

Average measure ICCs for all scores were in the excellent to good range using all 5 coders (ICCs $>0.65$ ) (Table 7). For the 2 experts, reliability was variable with poor reliability for Establishing Focus global measures and behaviour counts. Reliability was improved in these areas between the 3 non-experts. Scores for the strongest coder pair (expert vs. non expert 1), were also in the excellent to good range with the exception of EF counts (ICC $=0.52$ ).

\section{Disc ussion}

We have developed a practical tool for assessing focusing in Motivational Interviewing. Internal consistency analyses have led to a refinement of the measure in which the Establishing Focus global scale has been dropped. The Establishing Focus behaviour count has been retained and our data suggest reliable assessment. Our inter-rater reliability incidences were mostly in the good to excellent range and are encouraging given that we used real examples of consultation data, which were naturally affected by data quality and practice variability. MIFI's design complements the most widely used measure of MI fidelity [28] and may be used to facilitate training in settings where discussion about multiple change targets are common. The MIFI does not however capture measurement of the evoking process in MI and should not be considered therefore as a stand-alone measure of MI.

The poor reliability between our expert coding pair on the establishing focus global scale was interesting. The reasons for this are unclear, but observations of their raw score data suggests that these raters had differing tolerances for identifying discussion content that indicated talk of breastfeeding and discussion topic classified as “other”. Expert-coder 1, (LCop) was very familiar with the Mam-kind data, having conducted data coding for the parent study and described herself as "more lenient" in classifying discussion content as breastfeeding. In contrast, expert-coder 2 (JC) was less familiar with the data and more likely to classify talk as other topic. Others have also highlighted the difficulty with defining what constitutes a topic [49]. To obtain reliability, we included a topic descriptor that outlined the range of topics that would be considered evidence of breastfeeding discussions. For example, breastfeeding conversations included talk of benefits, drawbacks, family support, discomfort, cosleeping and skin-to-skin contact. In MI a topic is the focus of anticipated change and should map to programme outcomes, that is, be congruent with the intervention's theory of change [50,51].

We considered that, in MI, topics or change targets have four defining characteristics. First, they arise in the clinical encounter from three different sources: the patient, the practitioner or the clinical context [1]. MIFI is designed to work with topics arising from the clinical context or practitioner role, that is, the practitioner's agenda. Second, topics vary in the degree to which they are well formulated [1]. For example, in the practice of psychotherapy significant time might be spent formulating potential topics whereas in our dataset topics areas were more clearly defined. Third, where multiple topics might be addressed they would need to be prioritised [29]. For example, in discussing self-management of coronary heart disease patients may need to prioritise one change area from a menu of options such as smoking, diet, physical activity, or stress. MIFI can accommodate discussion of multiple practitioner agenda provided they are pre-specified. Fourth, topics vary in the degree to which they are specific. An analogy here is the focal point created by a spotlight compared with a laser. For example, a dietician may 
Table 7 Global ratings: intra-class coefficient - ICC (95\% confidence interval)

\begin{tabular}{|l|c|c|c|c|}
\hline Global measure & Overall & Expert group (n=2) & Non-expert group (n=3) & $\begin{array}{c}\text { Best coding pair - expert 1 } \\
\text { and non-expert }\end{array}$ \\
\hline Establishing Focus & 0.82 & 0.23 & 0.8 & 0.79 \\
$(0.66$ to 0.92$)$ & $(-0.96$ to 0.69$)$ & 0.78 & 0.59 to 0.92$)$ & 0.9 \\
$(0.44$ to 0.91$)$ & $(0.78$ to 0.96$)$ & 0.81 \\
\hline Holding Focus & 0.91 & 0.61 & 0.75 & 0.52 to 0.92$)$ \\
\hline $\begin{array}{l}\text { Developing depth and } \\
\text { momentum }\end{array}$ & 0.82 to 0.96$)$ & $(0.08$ to 0.84$)$ & 0.48 to 0.89$)$ & $(0.63$ to 0.94$)$ \\
\hline Partnership & 0.66 to 0.92$)$ & 0.45 & $(0.16$ to 0.82$)$ & 0.85 \\
\hline Empathy & $(0.38$ to 0.85$)$ & 0.0 .20 to 0.77$)$ & $(0.12$ to 0.8$)$ & 0.63 to 0.94$)$ \\
\hline Proportion score Feeding & $(0.43$ to 0.86$)$ & $(0.09$ to 0.86$)$ & 0.85 & 0.72 \\
\hline Establishing Focus counts & 0.93 & 0.87 & $(0.69$ to 0.94$)$ & 0.31 to 0.89$)$ \\
\hline
\end{tabular}

$<0.40=$ Poor reliability

$0.40-0.59=$ Fair reliability

$0.60-0.74=$ Good reliability

$>0.75=$ Excellent

address the broad area of menu planning with a patient who has diabetes but choose to focus more narrowly on sugar consumption. Clearly specified topics were required for reliable measurement using MIFI.

The development of MIFI has also allowed us to offer some conceptual clarity and a refinement of the focusing construct in MI. The need to focus or re-focus may arise at three time points: the opening of a conversation, at a conversational juncture, that is, when one topic has closed and another begins and at the close of a conversation [52]. In clinical practice, the opening [53-57] and closing segments [58] of interaction have been studied in depth to identify conversational patterning, which has in turn led to the development of person-centered communication strategies aimed at enhancing the collaborative nature of topic generation and formulation [29]. These strategies aim to enable practitioners to consciously establish mutual alignment on a topic, which will then define the parameters of shared attention and cognitive focus [49]. Early studies on doctor-patient interactions in medical settings revealed how topic control represents social power in a medical discourse by highlighting subtle processes through which clinicians controlled the discourse, focusing attention on areas they felt were relevant to the medical interview [53,59-61]. In this way, they revealed the conversational patterning that gave rise to a medically dominated discourse in which the patient's account was characterised by disruptions and discontinuities. These early studies laid fertile ground for identifying the micro-skills and sequences that might give rise to more person-centered practice to co-create the clinical encounter. These insights have informed communication skills training worldwide by articulating the effect of communication patterning and thereby informing effective practice [62-64].

Congruent with its patient-centered roots, in MI too the act of formulating and prioritising change targets is a collaborative process through which practitioner and patient goals are aligned. Alignment of goals may involve negotiating or prioritising the directions of the conversation and agenda mapping is often used to facilitate this [29]. Alternately, as in the work we describe in this paper, focusing may simply involve raising a subject explicitly to ensure transparency and collaboration. Once a focus has been established, the conversation should remain in that area allowing for exploration of the topic in a way that is meaningful and purposeful and developing a sense of momentum, forward movement or progress when discussing that topic [65]. In this way, focusing defines and enriches the conversation in readiness for and in support of evoking. Topic transitions during the course of a clinical encounter are common and conversation analytic studies reveal how these occur naturally in two ways: where an initiative device is used to signal a shift from one topic to the next or where the topic content branches out from a previous topic area [49]. We observed similar shifts in our data, which were mostly accommodated by a coding rule that required three consecutive interactions about a single topic to result in focus being established. We also noted that where these transitions were frequent and somewhat haphazard, practitioners and patients struggled to make progress in any single change area. Rather, practitioners need to navigate the conversation, maintaining focus on one topic area at a time, while remaining flexible and collaborative [29,66]. In earlier work we described these topic transitions as navigation [29]. This metaphor was designed for participants to retain a global awareness of the direction of the conversation, where it might move off course and how they might act responsively to allow for those shifts or gently steering it back. This involves attending to subtle interactional cues that steer the conversation in pre-determined but also, potentially, in new directions [67]. The MIFI offers a reliable approach to measuring the focusing construct, establishing a platform for empirical examination of these different dimensions.

Our research has both strength and limitations. First, an advantage of this work was our use of real rather than 
simulated consultation recordings in developing MIFI which allowed measure development to be informed by real examples of clinical practice. However, these data were from two projects focused on improving maternal and child health outcomes and further application of the measure in other settings is required. Second, the data we used to develop the measure were audio recorded as part of a process evaluation for studies. Video-recorded data were not available and we were not able to capture the nonverbal dimension of interactions. This limitation arose from pragmatic constraints of conducting the clinical studies, but informed, in part, our decision not to progress with formal conversation analysis at earlier stages of measure development. Richer insights regarding transitions on and off topics may have been obtained had we used this methodology. Third, our reliability analyses were limited to use of data with a single change target. While the measure theoretically is designed to assess multiple change targets in parallel, reliable measurement in this area requires further exploration. Fourth, applicability of the measure in briefer consultations requires testing. Finally, while we have established preliminary reliability of the measure, further validation of MIFI is required as is fieldtesting of using the measure and evaluations of training outcomes following its use.

\section{Conclusion}

We have developed MIFI, a new measure of focusing in Motivational Interviewing. The measure may help practitioners better understand and enact the focusing process in MI and may help trainers to teach it. The MIFI may be most useful in settings where a clear theory of change links programme goals to within session conversations that are formulated as change targets. Measure validation is planned in further work.

It is self evident that an MI intervention is unlikely to deliver change unless a conversation about that change occurs. We argue for a clear line of sight to be articulated between MI-informed interventions and programme outcomes. Conversations about change may need to be clearly formulated and prioritised in a way that does not inhibit patient-centered practice. As MI expands into other settings, focusing becomes an increasingly important skill for effective MI integration. In this paper we offer conceptual clarity about what that involves and have developed a tool that might help train practitioners and assess fidelity. MIFI may be of particular value for training practitioners to deliver interventions where many different discussion topics are anticipated, such as in maternal and child health services, social care and mental health settings. Tools such as the MIFI are essential too if we are to evaluate the utility and impact of integrating MI into such programmes.

\section{Acknowledgements and Conflicts of Interest}

We acknowledge Steve Martino, Ali Hall, Susan Butterworth, Casey Jackson, Manuel Campinez Navarro, Chris Wagner and Karen Ingersoll for sharing their measures and Christian Barlow for data coding. Mam-kind study reference number 13/18/05; Building Blocks ISRCTN23019866. We thank the Wellcome Trust (Institutional Strategic Support Fund) for funding. We declare no conflicts of interest.

\section{References}

[1] Miller, W.R. \& Rollnick, S. (2012). Motivational Interviewing - helping people change. New York: Guilford Press.

[2] Lindon-Hawley, N., Thompson, T.P. \& Begh, R. (2015). Motivational interviewing for smoking cessation. Cochrane Database of Systematic Reviews CD006936.

[3] Kohler, S. \& Hofmann, A. (2015). Can motivational interviewing in emergency care reduce alcohol consumption in young people? A systematic review and meta-analysis. Alcohol and Alcoholism 50 (2)107-117.

[4] Tanner-Smith, E.E. \& Lipsey, M.W. (2015). Brief alcohol interventions for adolescents and young adults: a systematic review and meta-analysis. Journal of Substance Abuse Treatment 51, 1-18.

[5] Lundahl, B., Moleni, T., Burke, B.L., Butters, R., Tollefson, D., Butler, C. \& Rollnick, S. (2013). Motivational interviewing in medical care settings: a systematic review and meta-analysis of randomized controlled trials. Patient Education and Counseling 93 (2)157-168.

[6] Rubak, S., Sandbæk, A., Lauritzen, T. \& Christensen, B. (2005). Motivational interviewing: a systematic review and meta-analysis. British Journal of General Practice 55 (513) 305-312.

[7] O'Halloran, P.D., Blackstock, F., Shields, N., Holland, A., Iles, R., Kingsley, M., Bernhardt, J., Lannin, N., Morris, M.E. \& Taylor, N.F. (2014). Motivational interviewing to increase physical activity in people with chronic health conditions: a systematic review and metaanalysis. Clinical Rehabilitation 28 (12) 1159-1171.

[8] Wilson, A., Nirantharakumar, K., Truchanowicz, E.G., Surenthirakumaran, R., MacArthur, C. \& Coomarasamy, A. (2015). Motivational interviews to improve contraceptive use in populations at high risk of unintended pregnancy: a systematic review and meta-analysis. European Journal of Obstetrics, Gynecology \& Reproductive Biology 191, 72-79.

[9] Lundahl, B.W., Kunz, C., Brownell, C., Tollefson, D. \& Burke, B.L. (2010). A Meta-Analysis of Motivational Interviewing: Twenty-Five Years of Empirical Studies. Research on Social Work Practice 20 (2) 137-160.

[10] Amrhein, P.C., Miller, W.R., Yahne, C.E., Palmer, M. \& Fulcher, L. (2003). Patient commitment language during motivational interviewing predicts drug use outcomes. 
Journal of Consulting and Clinical Psychology 71 (5) 862878.

[11] Moyers, T.B., Martin, T., Christopher, P.J., Houck, J.M., Tonigan, J.S. \& Amrhein, P.C. (2007). Patient Language as a Mediator of Motivational Interviewing Efficacy: Where Is the Evidence? Alcoholism: Clinical and Experimental Research 31, 40s-47s.

[12] Bear, J.S., Beadnell, B., Garrett, S.B., Hartzler, B., Wells, E.A. \& Peterson, P.L. (2008). Adolescent change Language within a Brief Motivational Intervention and Substance Use Outcomes. Psychology of Addictive Behaviors 22 (4) 570-575.

[13] Gaume, J., Gmel, G. \& Daeppen, J-B. (2008). Brief alcohol interventions: Do counsellors' and patients' communication characteristics predict change? Alcohol and Alcoholism 43 (1) 62-69.

[14] Apodaca, T.R. \& Longabaugh, R. (2009). Mechanisms of change in motivational interviewing: a review and preliminary evaluation of the evidence. Addiction 104 (5) 705-715.

[15] Gaume, J., Gmel, G., Faouzi, M. \& Daeppen, J-B. (2008). Counsellor behaviours and patient language during brief motivational interventions: a sequential analysis of speech. Addiction 103 (11) 1793-1800.

[16] Moyers, T.B., Martin, T., Houck, J.M., Christopher, P.J. \& Tonigan, J.S. (2009). From in-session behaviors to drinking outcomes: a causal chain for motivational interviewing. Journal of Consulting \& Clinical Psychology 77 (6) 1113-1124.

[17] Glynn, L.H. \& Moyers, T.B. (2010). Chasing change talk: the clinician's role in evoking patient language about change. Journal of Substance Abuse Treatment 39 (1) 6570.

[18] Robling, M., Bekkers, M-J., Bell, K., et al. (2016). Effectiveness of a nurse-led intensive home-visitation programme for first-time teenage mothers (Building Blocks): a pragmatic randomised controlled trial. Lancet 387 (10014) 146-155.

[19] Botting, B., Rosato, M. \& Wood, R. (1998). Teenage mothers and the health of their children. Population Trends 93, 19-28.

[20] Moffitt, T.E. (2002). Teen-aged mothers in contemporary Britain. Journal of Child Psychology and Psychiatry and Allied Disciplines 43 (6) 727-742.

[21] Channon, S., Bekkers, M-J., Sanders, J., CanningsJohn, R., Robertson, L., Bennert, K., Butler, C., Hood, K. \& Robling, M. (2016). Motivational interviewing competencies among UK family nurse partnership nurses: a process evaluation component of the building blocks trial. BMC Nursing 15 (1) 55.

[22] Paranjothy, S., Copeland, L., Merrett, L., Grant, A., Phillips, R., Gobat, N., Sanders, J., Fitzsimmons, D., Hunter, B., Regan, S., Playle, R., Brown, A., Tedstone, S., Trickey, H. \& Robling, M. (2017). A novel peer-support intervention using Motivational Interviewing for breastfeeding maintenance: a UK feasibility study. Health Technology Assessments 21 (77) 1-138.

[23] Streiner, D.L. \& Norman, G.R. (2003). Health Measurement Scales: A Practical Guide to their
Development and Use. Oxford: Oxford Medical Publications.

[24] Madson, M.B. \& Campbell, T.C. (2006). Measures of fidelity in motivational enhancement: a systematic review. Journal of Substance Abuse Treatment 31 (1) 67-73.

[25] Dobber, J., van Meijel, B., Barkhof, E., Scholte op Reimer, W., Latour, C., Peters, R. \& Linszen, D. (2015). Selecting an optimal instrument to identify active ingredients of the motivational interviewing-process. Journal of Psychosomatic Research 78 (3) 268-276.

[26] MINT Inc. (2016). Motivational Interviewing Network of Trainers. Ontario, Canada: MINT Inc.

[27] Moyers, T.B., Martin, T., Manuel, J.K., Hendrickson, S.M.L. \& Miller, W.R. (2005). Assessing competence in the use of motivational interviewing. Journal of Substance Abuse Treatment 28 (1) 19-26.

[28] Moyers, T.B., Rowell, L.N., Manuel, J.K., Ernst, D. \& Houck, J.M. (2016). The Motivational Interviewing Treatment Integrity Code (MITI 4): Rationale, Preliminary Reliability and Validity. Journal of Substance Abuse Treatment 65, 36-42.

[29] Gobat, N., Kinnersley, P., Gregory, J.W. \& Robling, M. (2015). What is agenda setting in the clinical encounter? Consensus from literature review and expert consultation. Patient Education and Counseling 98 (7) 822-829.

[30] Pett, M.A., Lackey, N.R. \& Sullivan, J.J. (2003). Making sense of factor analysis: the use of factor analysis for instrument development in health care research. London, UK: Sage Publishers.

[31] Shrout, P.E. \& Fleiss, J.L. (1979). Intraclass correlations: Uses in assessing rater reliability. Psychological Bulletin 86 (2) 420-428.

[32] Hallgren, K.A. (2012). Computing inter-rater reliability for observational data: An overview and tutorial. Tutorials in Quantitative Methods for Psychology 8, 23-34. [33] Cicchetti, D.V. (1994). Guidelines, criteria, and rules of thumb for evaluating normed and standardized assessment instruments in psychology. Psychological Assessment 6 (4) 284-290.

[34] Corps, I. (2011). IBM SPSS Statistics for Windows, Version 20.0. NY, USA: Armonk.

[35] Gobat, N., Kinnersley, P., Gregory, J.W., Pickles, T., Hood, K. \& Robling, M. (2015). Measuring clinical skills in agenda-mapping (EAGL-I). Patient Education and Counseling 98 (10) 1214-1221.

[36] Lane, C., Huws-Thomas, M., Hood, K., Rollnick, S., Edwards, K. \& Robling, M. (2005). Measuring adaptations of motivational interviewing: the development and validation of the behavior change counseling index (BECCI). Patient Education and Counseling 56 (2) 166173.

[37] McMaster, F. \& Resnicow, K. (2015). Validation of the one pass measure for motivational interviewing competence. Patient Education and Counseling 98 (4) 499-505.

[38] Campiñez Navarro, M., Pérula de Torres, L.Á., Bosch Fontcuberta, J.M., et al. (2016). Measuring the quality of motivational interviewing in primary health care encounters: The development and validation of the 
motivational interviewing assessment scale (MIAS). European Journal of General Practice 22 (3) 182-188.

[39] Di Clemente, C.C., Crouch, T.B., Norwood, A.E., Delahanty, J. \& Welsh, C. (2015). Evaluating training of screening, brief intervention, and referral to treatment (SBIRT) for substance use: Reliability of the MD3 SBIRT Coding Scale. Psychology of Addictive Behaviors 29 (1) 218-224.

[40] Jackson, C., Butterworth, S., Hall, A. \& Gilbert, J. (2015). Motivational Interviewing Competency Assessment (MICA1.2).

[41] Moyers, T.B., Martin, T., Manuel, J.K., Miller, W.R. \& Ernst, D. (2010). Motivational Interviewing Treatment Integrity 3.1.1 (MITI 3.1.1).

[42] Ledoux, T., Hilmers, A., Watson, K., Baranowski, T. \& O'Connor, T.M. (2013). Development and feasibility of an objective measure of patient-centered communication fidelity in a pediatric obesity intervention. Journal of Nutrition Education and Behavior 45 (4) 349-354.

[43] Ingersoll, K. \& Wagner, C.C. (2014). Rating the fidelity of MI groups sessions: the AMIGOS coding system. 4th International Conference on Motivational Interviewing, Amsterdam, 16-18 June.

[44] Miller, W.R., Moyers, T.B., Ernst, D. \& Amrhein, P. (2003). Manual for the Motivational Skill Code (MISC). Version 2.0.

[45] Miller, W.R., Moyers, T.B., Ernst, D. \& Amrhein, P. (2008). Manual for the Motivational Skill Code (MISC). Version 2.1.

[46] Martin, T., Moyers, T.B., Houck, J., Christopher, P. \& Miller, W.R. (2005). Motivational Interviewing Sequential Code for Observing Process Exchanges (SCOPE). Coder's Manual.

[47] Kahler, C.W., Caswell, A.J., Laws, M.B., Walthers, J., Magill, M., Mastroleo, N.R., Howe, C.J., Souza, T., Wilson, I., Bryant, K. \& Monti, P.M. (2016). Using topic coding to understand the nature of change language in a motivational intervention to reduce alcohol and sex risk behaviors in emergency department patients. Patient Education and Counseling 99 (10) 1595-1602.

[48] Moyers, T.B., Manuel, J.K. \& Ernst, D. (2014). Motivational Interviewing Treatment Integrity Coding Manual 4.2.

[49] Riou, M. (2015). A methodology for the identification of topic transitions in interaction. discours 16.

[50] Craig, P., Dieppe, P., Macintyre, S., Michie, S., Nazareth, I. \& Petticrew, M. (2008). Developing and evaluating complex interventions: the new Medical Research Council guidance. British Medical Journal 337, a1655.

[51] Moore, G.F., Audrey, S., Barker, M., Bond, L., Bonell, C., Hardeman, W., Moore, L., O’Cathain, A., Tinati, T., Wight, D. \& Baird, J. (2015). Process evaluation of complex interventions: Medical Research Council guidance. British Medical Journal 350, h1258.

[52] Button, G. \& Casey, N. (1985). Topic Nomination and Topic Pursuit. Human Studies 8 (1) 3-55.

[53] Beckman, H.B. \& Frankel, R.M. (1984). The effect of physician behavior on the collection of data. Annals of Internal Medicine 101 (5) 692-696.
[54] Marvel, M.K., Epstein, R.M., Flowers, K. \& Beckman, H.B. (1999). Soliciting the patient's agenda: Have we improved? Journal of the American Medical Association 281 (3) 283-287.

[55] Heritage, J. \& Robinson, J.D. (2006). The structure of patients' presenting concerns: physicians' opening questions. Health Communication 19 (2) 89-102.

[56] Heritage, J., Robinson, J.D., Elliott, M.N., Beckett, M. \& Wilkes, M. (2007). Reducing patients unmet concerns in primary care: the difference one word can make. Journal of General Internal Medicine 22 (10) 1429-1433.

[57] Robinson, J.D., Heritage, J., Robinson, J.D. \& Heritage, J. (2006). Physicians' opening questions and patients' satisfaction. Patient Education and Counseling 60 (3) 279-285.

[58] Robinson, J.D. (2001). Closing medical encounters: two physician practices and their implications for the expression of patients' unstated concerns. Social Science \& Medicine 53 (5) 639-656.

[59] Byrne, P.S. \& Long, B.E.L. (1976). Doctors Talking to Patients. London: RCGP Publications.

[60] Ainsworth-Vaughn, N. (1992). Topic transitions in physician-patient interviews: Power, gender, and discourse change. Language in Society 21 (3) 409-426.

[61] Mishler, E.G. (1984). The discourse of medicine. Westport, CT: Greenwood Publishing Group.

[62] Makoul, G.P. (2001). Essential Elements of Communication in Medical Encounters: The Kalamazoo Consensus Statement. Academic Medicine 76 (4) 390-393.

[63] Simpson, M., Buckman, R., Stewart, M., Maguire, P., Lipkin, M., Novack, D. \& Till, J. (1991). Doctor-patient communication: the Toronto consensus statement. British Medical Journal 303 (6814) 1385-1387.

[64] von Fragstein, M., Silverman, J.D., Cushing, A., Quilligan, S., Slisbury, H. \& Wiskin, C. (2008). UK consensus statement on the content of communication curricula in undergraduate medical education. Medical Education 42, 1100-1107.

[65] Wagner, C.C. \& Ingersoll, K.S. (2012). Motivational Interviewing in Groups. NY: Guildford Press.

[66] Mauksch, L.B., Dugdale, D.C., Dodson, S. \& Epstein, R. (2008). Relationship, communication, and efficiency in the medical encounter: creating a clinical model from a literature review. Archives of Internal Medicine 168 (13) 1387-1395.

[67] Peltenburg, M., Fischer, J.E., Bahrs, O., van Dulmen, S. \& van den Brink-Muinen, A. (2004). The unexpected in primary care: a multicenter study on the emergence of unvoiced patient agenda. Annals of Family Medicine 2 (6) 534-540. 